\title{
Aspect of Thoracoscopic Biopsy in Pleural Malignancy
}

\author{
Priyanka Joshi ${ }^{1}$, Rajdeep Dhandhukiya ${ }^{2}$, Sheema Maqsood ${ }^{3}$, Vijay Bhargava ${ }^{4}$ \\ ${ }^{1}$ Department of Pulmonary Medicine, Peoples Hospital, Bhopal, Madhya Pradesh, India. \\ ${ }^{2}$ Department of Pulmonary Medicine, B. J. Medical College, Ahmedabad, Gujarat, India. \\ ${ }^{3}$ Department of Pulmonary Medicine, RKDF University, Bhopal, Madhya Pradesh, India. \\ 4Jawahar Lal Nehru Cancer Hospital, Bhopal, Madhya Pradesh, India.
}

\section{ABSTRACT}

\section{BACKGROUND}

Medical thoracoscopy, in the educated fingers of a pulmonologist, is a secure and powerful process for the diagnosis and treatment of many pleural diseases. If the centres for thoracoscopy are available, thoracoscopy should be carried out on those undiagnosed sufferers due to its excessive sensitivity in malignant and tuberculous pleural effusions. That is why the ultimate decade witnessed an interest in thoracoscopy as a diagnostic device for pleural diseases. In the existing study, we wanted to describe our experience with the function of thoracoscopic biopsy in patients who underwent thoracoscopy for diagnostic purposes.

\section{METHODS}

The study protocol and ethical approval were taken by the Institutional Review Board for human studies of B. J. Medical College, Gujarat. It was a prospective study conducted in the Department of Pulmonary Medicine, B. J. Medical College, Ahmedabad, between July 2014 and November 2016. 39 patients who underwent medical thoracoscopy for undiagnosed pleural effusions were enrolled in this study. Undiagnosed pleural effusion was defined as failure to achieve a diagnosis by initial pleural fluid analysis including pleural fluid adenosine deaminase (ADA) levels and at least three pleural fluid analyses negative for malignant cells. Diagnostic pleural fluid aspiration was done to obtain pleural fluid specimens.

\section{RESULTS}

In the present study with the help of thoracoscopy, 36 (92.31\%) patients were diagnosed successfully while only 3 patients remained undiagnosed. In the present study, on thoracoscopic examination 21 (53.85 \%) patients had pleural nodules, 5 $(12.82 \%)$ patients had pleural thickening, $5(12.82 \%)$ patients had pleural plaquelike erythema. The remaining patients had other uncommon findings e.g. nonspecific pleuritis 3 (7.69\%).

\section{CONCLUSIONS}

Among all the patients with undiagnosed exudative pleural effusion, irrespective of smoking status which fails to respond to conventional medical management, diagnostic thoracoscopy should be considered as early as possible. The diagnostic yield of thoracoscopy for pleural pathology remains very high (92.3\%)

\section{KEYWORDS}

Diagnosis, Malignant Pleural Effusion, Thoracoscopy.
Corresponding Author: Dr. Sheema Maqsood, A 62, Dwarkadham, Airport Road, Bhopal-462011, Madhya Pradesh, India. E-mail: drsheemamaqsood@gmail.com

DOI: $10.14260 / \mathrm{jemds} / 2021 / 740$

How to Cite This Article:

Joshi P, Dhandhukiya R, Maqsood S, et al. Aspect of thoracoscopic biopsy in pleural malignancy. J Evolution Med Dent Sci 2021;10(42):3649-3653, DOI: $10.14260 / \mathrm{jemds} / 2021 / 740$

Submission 10-09-2021,

Peer Review 05-10-2021,

Acceptance 12-10-2021,

Published 18-10-2021.

Copyright @ 2021 Priyanka Joshi et al. This is an open access article distributed under Creative Commons Attribution License [Attribution 4.0 International (CC BY 4.0)] 


\section{BACKGROUND}

The correct diagnosis of the pleural disease is a vast challenge. Conservative estimates propose that $25 \%$ of diseases visible in a pulmonologist's practice contain the pleura. Of those cases, $25 \%$ of them are not able to be attributed to a specific diagnosis, even after thoracentesis and closed pleural biopsy. As many as $50 \%$ of the sufferers of these undiagnosed diseases will subsequently be recognized with a malignancy. If the centres for pleuroscopy/thoracoscopy are available, thoracoscopy needs to be carried out on those undiagnosed sufferers due to its excessive sensitivity in malignant and tuberculous pleural effusions. That is why the ultimate decade witnessed an interest in thoracoscopy as a diagnostic device for pleural diseases. Medical thoracoscopy also named pleuroscopy as an endoscopic examination of the pleural space. It is a least invasive procedure that was first invented in 1910 by Hans Christian Jacobaeus. $\mathrm{He}$ is called as the "Father of Thoracoscopy." Jacobaeus published an early report on the use of thoracoscopy to localize and diagnose the pleural disease. ${ }^{1}$

Before the application of thoracoscopy, hydrothorax exfoliative cytologic examination and closed pleural biopsy were the two methods typically used; however, these methods have a low positive diagnostic rate. ${ }^{2}$ The clinical application of thoracoscopy thus provides a novel diagnostic method for undiagnosed pleural effusions. Compared to conventional closed pleural biopsy, thoracoscopy has notable advantages. It overcomes the blindness of closed pleural biopsy and markedly improves the diagnostic accuracy of pleural effusions, and therefore improves the positive diagnostic rate of pleural diseases.3,4,5 Medical thoracoscopy, with inside the educated fingers of a pulmonologist, is a secure and powerful investigation for the diagnosis and treatment of many pleural diseases. It is typically done in a bronchoscopy suite, with anaesthetic and aware sedation, with cardiopulmonary tracking and without intubation or mechanical ventilation.

It lets one visualise the complete pleural floor and carry out confined diagnostic and healing procedures. The most important indication for thoracoscopy is an assessment of exudative pleural effusions which stay undiagnosed after pleural fluid analysis, in which thoracoscopy is recommended as an alternative to closed pleural biopsy. With thoracoscopy, you can visualize the complete visceral and parietal pleura and take a pleural biopsy from involved sites below vision. The diagnostic yield is with inside the order of 91-95\% for malignancy and may be as excessive as $100 \%$ for pleural tuberculosis. Although thoracoscopy may be used to visualise pleural blebs and bullae in sufferers with spontaneous pneumothorax, that is seldom the indication for thoracoscopy.

Medical thoracoscopy may be used for therapeutic procedures, consisting of adhesiolysis and evacuation of pleural fluid in sufferers with empyema, pleurodesis in sufferers with recurrent pleural effusion and spontaneous pneumothorax. In the existing study, we described our experience with the function of thoracoscopic biopsy in patients who underwent thoracoscopy for diagnostic purposes.

\section{METHODS}

This was a prospective cross-sectional study conducted in the Department of Pulmonary Medicine, B. J. Medical College, Ahmedabad, Gujarat between July 2014 and November 2016. The study protocol and ethical approval were taken by the Institutional Review Board for human studies. Total 39 patients who underwent medical thoracoscopy for undiagnosed pleural effusions were enrolled in this study. The pleural fluid which had failed to achieve a diagnosis by initial pleural fluid analysis including pleural fluid adenosine deaminase (ADA) levels and at least three pleural fluid analyses negative for malignant cells was called undiagnosed pleural effusion in this study.

Detailed clinical evaluation with history was taken and clinical examination was done. A pleural fluid examination was done for diagnosis to obtain pleural fluid specimens. Differential cell counts, protein, adenosine deaminase (ADA), cytological examination, gram-stain, Ziehl-Neelsen stain were performed. Serum was taken at the same time for the measurement of protein levels. A computed tomography scan (CT) of the chest was performed on all patients to assess whether thoracoscopy can be done or not.

\section{Inclusion Criteria}

In the current study, only those patients were enrolled who failed to respond to initial fifteen days of conventional medical management, remained symptomatic (after repeated thoracocentesis/ATT/antibiotics), found fit for the medical thoracoscopy with good performance status, however, breathlessness alone was not necessarily a contraindication as dyspnoea secondary to the effusion was relieved by the procedure. Patients with baseline SpO2 $>90$ $\%$, without bleeding coagulopathy (PT with INR $<2$ ) were enrolled.

\section{Exclusion Criteria}

- Patients with transudative pleural effusion, according to Light's criteria.

- Patients whose initial pleural fluid examination through thoracocentesis or closed pleural biopsy could reach a definitive histopathological diagnosis.

- Patients who were not fit for performing thoracoscopy as in the following cases: Patients with severe uncorrected hypoxemia despite continuous oxygen administration.

- Patients who could not withstand the lateral decubitus for a period long enough to perform a thoracoscopy.

- Patients with unstable cardiovascular and haemodynamic status.

For patients with coagulative defects, at least the prothrombin concentration should be greater than $60 \%$, and the platelet count should be greater than 60,000 .

The patient was asked to lie in the lateral decubitus position breathing spontaneously, with the normal lung in the dependent position and the arm raised above the head. The side of the chest which had to be examined was disinfected; $15-30 \mathrm{ml}$ of lidocaine $2 \%$ was injected at the 
point of entry, through all layers of chest wall up to the pleura. Pleural fluid aspiration was done to confirm the presence of pleural fluid at the insertion site. A single puncture, $1-\mathrm{cm}$ incision was made in the mid-axillary line between the 4 th and 7 th intercostal spaces of the chest wall, and a track was created by blunt dissection. A trocar was inserted at the site and the pleural cavity opened to atmospheric pressure, any remaining pleural fluid was aspirated. The pleural cavity was fully examined, and biopsy specimens of parietal pleura were taken as appropriate under direct vision. Multiple biopsy samples were taken to avoid any bias towards any technique. It took more time to obtain an equal number of biopsies using the flexible thoracoscope. At the end of the procedure, a chest tube was inserted, and lung expansion was radiographically confirmed and after that chest tube was removed. A chest radiograph was done within $24 \mathrm{~h}$. Patients were put under close observation post pleuroscopy, any complication was reported and dealt with. The pleural biopsy obtained with the two instruments was processed individually.

Specimens were fixed in $10 \%$ neutral buffered formalin. The specimen sent for pathology was put separately in normal saline. Later on, all specimens were randomly examined by a pathologist irrespective of the biopsy method but knowing clinical history. The acceptability of specimens and tissue diagnosis was noted. When the pleural biopsy was conclusively positive for malignancy it was labelled as malignant effusion. A final diagnosis was made with biopsy findings regarding both histopathological and microbiological examinations and further investigations were made according to individual patient requirements and the subsequent clinical course.

\section{Statistical Analysis}

Qualitative data were analysed by a frequency table. Percentage was calculated for each category. For the analysis purpose, MS Excel 2013 was utilized.

\section{RESULTS}

The age and sex distribution of the study population are listed in Table 1.

\begin{tabular}{|c|c|c|c|c|c|c|}
\hline $\begin{array}{l}\text { Age Group } \\
\text { (Years) }\end{array}$ & Male & $\%$ & Female & $\%$ & $\begin{array}{l}\text { No. of } \\
\text { Cases }\end{array}$ & $\begin{array}{c}\text { Percentage } \\
(\%)\end{array}$ \\
\hline $21-30$ years & 2 & 5.13 & 1 & 2.56 & 3 & 7.69 \\
\hline $31-40$ years & 2 & 5.13 & 3 & 7.69 & 5 & 12.82 \\
\hline 41-50 years & 5 & 12.82 & 1 & 2.56 & 6 & 15.38 \\
\hline $51-60$ years & 8 & 20.52 & 4 & 10.26 & 12 & 30.78 \\
\hline$\geq 61$ years & 10 & 25.64 & 3 & 7.69 & 13 & 33.33 \\
\hline Total & 27 & 69.24 & 12 & 30.76 & 39 & 100 \\
\hline \multicolumn{7}{|c|}{ Table 1. Age \& Sex Distribution } \\
\hline
\end{tabular}

Between July 2014 and November 2016, 39 patients with undiagnosed pleural effusion successfully underwent medical thoracoscopy.

In the current study, persistent pleural effusion was found among farmers 10 (25\%), followed by housewives and labourers with $9(23.07 \%)$ and $5(12.82 \%)$ respectively (Table 2).

\begin{tabular}{|ccc|}
\hline Occupation & No. of cases & Percentage \\
\hline Farmer & 10 & $25 \%$ \\
House wife & 9 & $23.07 \%$ \\
Labourer & 5 & $12.82 \%$ \\
Factory worker & 3 & $7.69 \%$ \\
Teacher & 2 & 5.13 \\
Carpenter & 1 & 2.56 \\
Student & 2 & 5.13 \\
Air force officer & 1 & $2.56 \%$ \\
Govt Employee & 1 & $2.26 \%$ \\
Security work & 1 & $2.56 \%$ \\
Peon & 1 & $2.56 \%$ \\
Driver & 1 & $2.56 \%$ \\
Juice maker & 1 & $2.56 \%$ \\
Lab registrar & 1 & $2.56 \%$ \\
Total & $\mathbf{3 9}$ \\
\hline \multicolumn{2}{|c|}{} \\
\hline
\end{tabular}

From the present study, it was observed that dyspnoea, chest pain and dry cough were the commonest complaints. Dyspnoea was found among 29 (74.36\%), chest pain 25 (64.10\%) and dry cough in $25(64.10 \%)$ patients. (Table 3$)$.

\begin{tabular}{|ccc|}
\hline Symptoms & No. of cases & Percentage \\
Dyspnoea & 29 & $74.36 \%$ \\
Dry cough & 25 & $64.10 \%$ \\
Chest pain & 25 & $64.10 \%$ \\
Anorexia & 19 & $48.72 \%$ \\
Fever & 18 & $46.15 \%$ \\
Weight loss & 15 & $38.46 \%$ \\
Clubbing & 8 & $20.51 \%$ \\
Haemoptysis & 7 & $17.95 \%$ \\
Others e.g. joint pain, hoarseness of voice, & 5 & $12.82 \%$ \\
swelling of the breast) & 5 \\
\hline Table 3. Clinical Presentation of Patient \\
\hline \multicolumn{2}{|c}{} \\
\hline
\end{tabular}

The majority of the patients had symptoms for less than 1 month (Table 4).

\begin{tabular}{|ccc|}
\hline Duration & No. of cases & Percentage \\
Less than 1 month & 28 & $71.79 \%$ \\
1-2 month & 9 & $23.08 \%$ \\
2-3 month & 2 & $5.13 \%$ \\
>3 month & 0 & $0 \%$ \\
Total & $\mathbf{3 9}$ & $\mathbf{1 0 0} \%$ \\
\hline \multicolumn{3}{|c}{ Table 4. Duration of Symptoms } \\
\hline
\end{tabular}

On gross examination, 21 (53.85\%) were hazy and 11 $(28.20 \%)$ were turbid while 7 (17.95\%) were clear. On macroscopic appearance, 21 (53.85\%) were hemorrhagic followed by 16 (41.03\%) who were yellowish (Table 5).

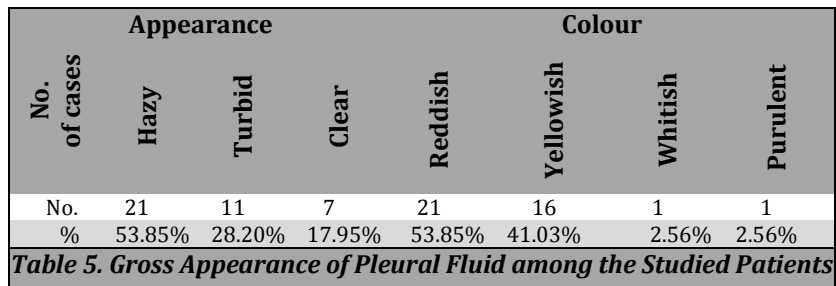

In the current study, 25 (64.11\%) had lymphocytic predominance followed by 13 (33.33) who had neutrophilic predominance (Table 6).

\begin{tabular}{|ccc|}
\hline Predominant cells & No & $\mathbf{\%}$ \\
Neutrophilic predominance & 13 & $33.33 \%$ \\
Lymphocytic predominance & 25 & $64.11 \%$ \\
Other(mesothelial) cells predominance & 1 & $2.56 \%$ \\
Total & $\mathbf{3 9}$ & $\mathbf{1 0 0} \%$ \\
\hline Table 6. Distribution of Studied Patients According to Predominant \\
Cells Present in Pleural Fluid & \\
\hline
\end{tabular}

The characteristics of the pleural fluid in the present study were exudative, predominantly lymphocytic with mean cell count 962.692 cells/dl, mean protein 4.52 (g/dl), mean glucose $63.66(\mathrm{mg} / \mathrm{dl})$ and mean ADA as 32.98 (Table 7). 


\begin{tabular}{|cc|}
\hline Analysis & Mean value \\
Cell count & Lymphocytes $60.00 \%$ \\
Protein $(\mathrm{g} / \mathrm{dl})$ & Polymorph $46.15 \%$ \\
Glucose $(\mathrm{mg} / \mathrm{d})$ & 4.52 \\
ADA (U/L) & 63.66 \\
\hline Table 7. Pleural Fluid Biochemical Characteristics in Malignancy \\
\hline
\end{tabular}

In the present study on thoracoscopic examination, 21 (53.85 \%) patients had pleural nodules, 5 (12.82\%) patients had pleural thickening, 5 (12.82\%) patients had pleural plaque-like erythema. The remaining patients had other uncommon findings e.g. nonspecific pleuritis 3 (7.69 \%) (Table 8).

\begin{tabular}{|ccc|}
\hline Thoracoscopic findings & No. of Cases & $\mathbf{\%}$ \\
Pleural nodules & 21 & $53.85 \%$ \\
Pleural thickening & 5 & $12.82 \%$ \\
Plaque like erythema & 5 & $12.82 \%$ \\
Normal pleura/nonspecific findings & 3 & $7.69 \%$ \\
Adhesion & 2 & $5.13 \%$ \\
Black brown patches & 1 & $2.56 \%$ \\
Purulent & 2 & $5.13 \%$ \\
\hline Table 8. Gross Thoracoscopic Findings in the Studied Group \\
\hline
\end{tabular}

Out of 39 cases, thoracoscopy helped in the diagnosis of 36 patients. $22(56.41 \%)$ patients were diagnosed with pleural malignancy, 6 (15.38 \%) patients were pleural tuberculosis, 8 patients $(20.52 \%)$ had nonspecific inflammatory pleuritis. $3(7.69 \%)$ patients were found to have normal pleura or no definite diagnosis. (Table 9)

\begin{tabular}{|ccc|}
\hline Tuberculosis & 6 & $15.38 \%$ \\
Inflammation (nonspecific pleuritis) & 8 & $20.52 \%$ \\
No definite diagnosis / normal & 3 & $7.69 \%$ \\
Total & $\mathbf{3 9}$ & $\mathbf{1 0 0} \%$ \\
\hline Table 9. The Histopathological Results Obtained by Thoracoscopic \\
Pleural Biopsy in the Studied Group \\
\hline
\end{tabular}

The most common type of malignancy obtained by thoracoscopic pleural biopsy in the studied group was metastatic adenocarcinoma among 12 (54.54\%) patients; the next common type of malignancy was malignant mesothelioma (3 out of 22) (13.65\%). Squamous cell carcinoma among 3 (13.65 \%). Remaining four patients with uncommon malignancy, 1 patient was diagnosed as a round cell tumour (4.54\%), metastatic breast adenocarcinoma (4.54\%), 1 small cell carcinoma (4.54\%) and 1 metastatic parotid adenoid cystic carcinoma (4.54\%) respectively. (Table 10)

\begin{tabular}{|ccc|}
\hline Histopathology $(\mathbf{N}=\mathbf{3 2})$ & No. & $\%$ \\
Metastatic adenocarcinoma & 12 & $54.54 \%$ \\
Malignant mesothelioma & 3 & $13.65 \%$ \\
Squamous cell carcinoma & 3 & $13.65 \%$ \\
Small cell carcinoma & 1 & $4.54 \%$ \\
Round cell tumour & 1 & $4.54 \%$ \\
Metastatic breast adenocarcinoma & 1 & $4.54 \%$ \\
Metastatic Parotid adenoid cystic carcinoma & 1 & $4.54 \%$ \\
\hline Table 10. Histological Types of Malignancy in the Studied Group \\
\hline
\end{tabular}

In the present study with the help of thoracoscopy, 36 (92.31\%) patients were diagnosed successfully while only 3 patients remained undiagnosed. (Table 11)

\begin{tabular}{|ccc|}
\hline & No. & $\%$ \\
Diagnosed & 36 & $92.31 \%$ \\
Undiagnosed & 3 & $6 \%$ \\
\hline Table 11. Diagnostic Yield of the Medical Thoracoscopy in the \\
& Studied Group & \\
\hline
\end{tabular}

Out of 39 patients, 17 patients (43.59\%) who underwent thoracoscopy had the commonest complication observed as pain, 4 patients $(10.26 \%)$ were found to have dyspnoea, in 3 patients (7.69\%) fever and minor bleeding occurred in 4 patients (10.26\%) (Table 12$)$.

\begin{tabular}{|c|cc|}
\hline Complications & No. & $\%$ \\
Pain & 17 & $43.59 \%$ \\
Minor bleeding & 4 & $10.26 \%$ \\
Dyspnoea & 4 & $10.26 \%$ \\
Fever & 3 & $7.69 \%$ \\
\hline Table 12. A Post-Thoracoscopic Complication in the Studied Group \\
\hline
\end{tabular}

\section{DISCUSSION}

Cytologic examination of pleural fluid is the first recommendation in a patient with undiagnosed pleural effusion which is suspected as malignant. Repeated thoracentesis can enhance the sensitivity of cytology, but it is usually only 50 to $70 \%$.

In the present study, the diagnostic yield of medical pleuroscopy was found to be $92.31 \%$ which is comparable with Prabhu et al. ${ }^{6}$ (97\%), L. A. Helala et al. ${ }^{7}$ (95\%), Mehta et al. ${ }^{8}(80 \%)$, Thangakunam ${ }^{9}(66.75 \%)$ study groups.

In the present study, malignancy was the most common histopathological diagnosis (56.41\%) which is comparable with Nattusamy et al. ${ }^{10}$ (62.5 \%), Mootha et al. ${ }^{11}$ (48.57\%) while TB was $15.38 \%$ comparable with Mootha et al. ${ }^{11} 22.85$ $\%$. Nonspecific pleuritis was $20.52 \%$ comparable with Nattusamy et al. ${ }^{10}$ (29.17 \%) and Mootha et al. ${ }^{11}$ (25.71\%).

Metastatic adenocarcinoma was the commonest diagnosis (54.54 \%) which is comparable with other studies i.e. Prabhu et al. ${ }^{6}(62.5 \%)$, Thangakunam et al. ${ }^{9}(75 \%)$ and Nattusamy et al. ${ }^{10}(35.42 \%)$ study groups. In the present study, malignant mesothelioma was the second most common diagnosis $(13.65$ \%) comparable with Prabhu et al. ${ }^{6}(12.5 \%)$, Thangakunam et al. ${ }^{9}$ (12.5\%). Small cell carcinoma was $4.54 \%$ comparable with Nattusamy ${ }^{10} \quad(6.25 \%)$. Metastatic breast adenocarcinoma was $4.54 \%$ comparable with $6.25 \%$.

In the present study, the most common thoracoscopic finding was pleural nodularity $(53.85 \%)$ which is comparable with other studies done by Nattusamy et al. (88 $\%)$. Other commonest finding was diffuse pleural thickening $(12.82 \%)$ which is again comparable with the study by Mehta et al. ${ }^{8}$ which showed similar findings among $7.89 \%$ of the patients. Another nonspecific thoracoscopic finding was adhesion (5.13\%) of the patients which is comparable with the study of Mehta et al. ${ }^{8}$ with similar findings among 15.78 $\%$ of patients.

Regarding biochemical characteristics of pleural fluid, the present study showed the mean total leukocyte count as 962.692 , the mean protein was 4.52 which is comparable with V. K. Mootha et al. and Nattusamy et al. study groups which obtained TLC 1525 and 1109 respectively while protein was 4.89 and 4.58 respectively. The mean sugar of the fluid was 63.66 which is comparable with V. K. Mootha et al. study group (72.22), mean ADA of the fluid was 32.98 which is comparable with V. K. Mootha et al. study group (39.1)

In the present study, the post pleuroscopy complications were postoperative pain (43.59\%), fever, minor bleeding, dyspnoea which is comparable with M. M. A. M. Shaheen et al. ${ }^{12}$ (40\%) study group. 


\section{CONCLUSIONS}

Diagnostic thoracoscopy is considered the gold standard for the diagnosis of pleural malignancy. The use of diagnostic thoracoscopy helps in the early diagnosis of pleural malignancy and prevents wrong treatment. Among all the patients with undiagnosed exudative pleural effusion, irrespective of smoking status which fails to respond to conventional medical management, diagnostic thoracoscopy should be considered as early as possible. The diagnostic yield of thoracoscopy for pleural pathology remains very high (92.3\%).

Data sharing statement provided by the authors is available with the full text of this article at jemds.com.

Financial or other competing interests: None.

Disclosure forms provided by the authors are available with the full text of this article at jemds.com.

\section{REFERENCES}

[1] McGrath EE, Anderson PB. Diagnosis of pleural effusion: a systematic approach. Am J Crit Care 2011;20(2):11928.

[2] Prakash UB, Reiman HM. Comparison of needle biopsy with cytologic analysis for the evaluation of pleural effusion: analysis of 414 cases. Mayo Clin Proc 1985;60(3):158-64.

[3] Kendall SW, Bryan AJ, Large SR, et al. Pleural effusions: is thoracoscopy a reliable investigation? A retrospective review. Respir Med 1992;86(5):437-40.
[4] Rodriguez-Panadero F, Janssen JP, Astoul P. Thoracoscopy: general overview and place in the diagnosis and management of pleural effusion. Eur Respir J 2006;28(2):409-22.

[5] Tassi GF, Tschopp JM. The centenary of medical thoracoscopy. Eur Respir J 2010;36(6):1229-31.

[6] Prabhu VG, Narasimhan R. The role of pleuroscopy in undiagnosed exudative pleural effusion. Lung India 2012;29(2):128-30.

[7] Helala LA, El-Assal GM, Frghally AA, et al. Diagnostic yield of medical thoracoscopy in cases of undiagnosed pleural effusion in Kobri El-Kobba Military Hospital Egypt. J Chest Dis Tuberc 2014;63(3):629-34.

[8] Mehta A, Rajesh V, Vishwam D, et al. Value of semirigid pleuroscopy in pleural effusion. Pulmon 2010;12(2):43-5.

[9] Thangakunam B, Christopher DJ, James P, et al. Semi-rigid pleuroscopy: initial experience from a tertiary care hospital. Indian J Chest Dis Allied Sci 2010;52(1):25-7.

[10] Nattusamy L, Madan K, Mohan A, et al. Utility of semirigid thoracoscopy in undiagnosed exudative pleural effusion. Lung India 2015;32(2):119-26.

[11] Mootha VK, Agarwal R, Singh N, et al. Medical thoracoscopy for undiagnosed pleural effusions: experience from a tertiary care hospital in north India. Indian J Chest Dis Allied Sci 2011;53(1):21-4.

[12] Shaheen MMAM, Shaaban AY, Mahmoud MI, et al. The diagnostic role of thoracoscope in undiagnosed pleural effusion: rigid versus flexible. Egypt J Chest Dis Tuberc 2014;63(3):635-42. 